\title{
TIPOLOGI KAWASAN BERISIKO BANJIR DI DAERAH ALIRAN SUNGAI (DAS) KALI PEPE, KOTA SURAKARTA
}

\author{
Typology of Flood Impacted Area in Kali Pepe River Basin, \\ Surakarta City
}

\section{Nur Miladan ${ }^{1}$, Kusumaningdyah Nurul Handayani $^{2}$ and Dewa Putu Aris Sadana ${ }^{1}$}

\author{
Diterima: 21 Oktober 2017 Disetujui: 11 April 2018
}

\begin{abstract}
Abstrak: Banjir merupakan bencana yang paling dominan terjadi di dunia dan fenomena ini terus berlangsung hingga saat ini. Sejauh ini, pengurangan risiko banjir di kawasan perkotaan melalui pendekatan-pendekatan mitigasi struktural dan non struktural. Pendekatan mitigasi tata ruang sangat perlu dipertimbangkan dalam manajemen risiko banjir disamping pendekatan-pendekatan tersebut. Transformasi keruangan (pola penggunaan lahan), serta daya dukung lingkungan dapat digunakan untuk mewujudkan pendekatan tata ruang dalam manajemen risiko bencana. Penelitian ini bertujuan menganalisis tipologi kawasan berisiko banjir di Daerah Aliran Sungai Kali Pepe, Kota Surakarta. Penelitian ini menggunakan pendekatan deduktif dengan metode kuantitatif yang didukung analisis spasial. Hasil penelitian menunjukkan terdapat 42 jenis ruang, namun demikian hanya 18 jenis yang berisiko banjir. Karakteristik lahan cenderung tidak berkorelasi terhadap intesitas dampak banjir. Pola penggunaan lahan dan karakteristik drainase memiliki kecenderungan berkorelasi terhadap risiko dampak banjir. Penataan ruang dapat difokuskan pada kawasan-kawasan permukiman perkotaan, utamanya kawasan-kawasan yang memiliki intensitas kepadatan bangunan tinggi. Sebaiknya pembatasan ruang terbangun dilakukan di sekitar daerah aliran sungai, dan rekayasa infrastruktur memperhatikan sistem hulu-hilir aliran sungai.
\end{abstract}

\section{Kata Kunci : Tipologi kawasan, daerah aliran sungai, risiko banjir}

\begin{abstract}
Flooding is the most dominant disaster in the world and it takes place until recently. So far, the urban flood reduction is carried out through the structural and non structural mitigation approaches. The spatial mitigation approach is very needed to be considered in the flood risk management besides those approaches. The spatial transformation (land use pattern), and environmental carrying capacity can be used to realize the spatial approach in disaster risk management. This research aims to analyze the flood risk area typology in Kali Pepe River Basin, Surakarta City. It uses deductive approach with quantitative methods being supported by spatial analysis. The results indicate there are 42 spatial types, but only 18 types being the flood risk areas. Land caracteristic tends to be not correlated to the flood impact intensity. Land use pattern and drainage caracteristics have a tendency to be correlated to the flood impact risk. The spatial planning could be focused on urban settlements, especially in areas with high building densities The built-up space restrictions should be implemented in the river sourrounding areas, and the infrastructure engineering concern with the river upstream-downstream system.
\end{abstract}

Keyword: area typology, river basin, flood risk

\footnotetext{
${ }^{1}$ Perencanaan Wilayah dan Kota, Fakultas Teknik, Universitas Sebelas Maret

${ }^{2}$ Arsitektur, Fakultas Teknik, Universitas Sebelas Maret
} 


\section{PENDAHULUAN}

Pada saat ini, perubahan iklim adalah salah satu isu penting yang menjadi perhatian masyarakat dunia. Perubahan iklim tersebut meningkatkan risiko bencana seperti banjir, kekeringan, badai, dan sebagainya. Banjir merupakan bencana yang sangat signifikan terjadi di dunia selama satu dekade terakhir, serta menimbulkan kerugian dan kerusakan yang sangat luas baik di negara-negara berkembang maupun negara-negara maju (Wisner et al., 2003). Banjir adalah luapan atau genangan yang berasal dari suatu sungai atau badan air, dan seringkali mengancam kehidupan masyarakat dan aset-asetnya (Hong et al, 2013). Lebih dari $50 \%$ dari kejadian banjir secara global terjadi di Asia (Tingsanchali, 2011).

Pendekatan mitigasi banjir secara struktural adalah bentuk teknologi yang sering digunakan (dan dianggap penting) pada pengelolaan kawasan perkotaan intensitas tinggi (padat), namun juga berisiko banjir (Gilbuena Jr et al, 2013). Sedangkan pendekatan mitigasi banjir non-struktural berorientasi pada kebijakan dan peraturan yang bertujuan untuk meningkatkan kapasitas masyarakat dalam pengelolaan risiko bencana. Perencanaan dan kebijakan penggunaan lahan juga merupakan upaya (mitigasi) non-struktural dan preventif (Mohit \& Sellub, 2013). Namun demikian, perencanaan dan kebijakan penggunaan lahan dalam pengelolaan dan mitigasi risiko bencana mengalami berbagai kendala pada penerapannya. Hal ini dikarenakan minimnya wawasan keilmuan model rekayasa tata ruang dalam manajemen risiko banjir. Perencanaan ruang (lahan) pada kawasan berisiko banjir, selama ini masih hanya menekankan pada kriteria umum/ konsep-konsep teoritis tentang perencanaan ruang terbuka hijau (RTH) dan infrastruktur (mitigasi struktural). Pendekatan mitigasi non struktural di berbagai kota seperti sistem peringatan dini, asuransi (insurance), dan pengendalian penggunaan lahan (ruang) hanya diterapkan sebagai upaya tambahan (supplementary) untuk pengendalian banjir (Liao, K. et al , 2016). Hal ini menunjukkan juga bahwa kajian mendalam mengenai alternatif permodelan tata ruang pada kawasan berisiko banjir masih belum banyak diungkap oleh para peneliti. Bertolak pada latar belakang tersebut, maka penelitian ini memfokuskan pada ekplorasi tipologi ruang dalam manajemen risiko banjir guna mewujudkan wilayah atau kota yang berkelanjutan. Penelitian ini melalui studi kasus Kota Surakarta. Kondisi geografis Kota Surakarta yang berbatasan dengan Bengawan Solo, dan juga memiliki beberapa sungai yang mengalir di dalam kota tersebut menyebabkan kota ini memiliki risiko tinggi dari bencana banjir. Fakta kejadian banjir dengan intensitas tinggi tercatat seperti pada Tahun 1966, 2007, dan 2016. Pengkajian tipologi ruang tersebut akan difokuskan pada Daerah Aliran Sungai (DAS) Kali Pepe yang membentang di Kota Surakarta. Ditinjau dari aspek penggunaan lahan, DAS ini melewati kawasan-kawasan pusat perkotaan Surakarta yang memiliki intensitas tinggi dari penduduk dan bangunan, sehingga daerah memiliki kerentanan tinggi dari banjir.

Pada penelitian ini fokus pada tipologi ruang kawasan berisiko banjir dalam mewujudkan kota yang berkelanjutan ditinjau dari aspek daya dukung lingkungan. Daya dukung lingkungan dinilai menurut ambang batas kesanggupan lahan sebagai suatu ekosistem menahan kerusakan dan kepunahan akibat penggunaannya. Daya dukung lingkungan dapat dilihat dari karakteristik lahan dan drainase, karakteristik banjir, dan juga pola penggunaan lahan. Perubahan tata guna lahan yang ada di dalam DAS dapat berpengaruh terhadap karakteristik dan frekuensi banjir pada DAS tersebut (Indarto, 2016).

\section{METODE PENELITIAN}

Pendekatan penelitian yang digunakan adalah pendekatan deduktif. Hasil penelitian tersebut, nantinya akan menjawab atas hipotesa yang dilakukan di awal (Bryman, 2004). Dalam penelitian ini dilakukan beberapa tahapan analisis dengan memperhatikan faktorfaktor fisik ruang di Kawasan DAS Kali Pepe. Beberapa tahapan analisis tersebut meliputi analisis karakateristik lingkungan (lahan dan drainase), analisis pola penggunaan lahan, 
analisis karakteristik banjir, dan analisis tipologi kawasan berisiko banjir. Sedangkan teknik analisis yang digunakan adalah scoring dan spasial. Teknik scoring dilakukan dengan cara memberi nilai pada setiap karakteristik lahan, pola penggunaan lahan, dan karakteristik drainase/ sungai. Pemberian penilaian terhadap karakteristik lingkungan, karakteristik pola penggunaan lahan, karakteristik banjir tersebut didasarkan teori dan peraturan-peraturan nasional terkait. SK Mentan NO. 837/KPTS/UI/UM11/1980 dan No. 683/KPTS/UM/8/1981 digunakan untuk menilai karakteristik lahan. Sedangkan penilaian karakteristik drainase (sungai) didasarkan pada kekerasan permukaan sungai dipengaruhi oleh adanya bebatuan, vegetasi, dan sampah (Indarto, 2016). Peraturan Menteri Pekerjaan Umum Nomor 12/Prt/M/2014 tentang Penyelenggaraan Sistem Drainase Perkotaaan digunakan untuk memberi penilaian terhadap karakteristik banjir.

\section{Tabel 1. Kerangka Analisis}

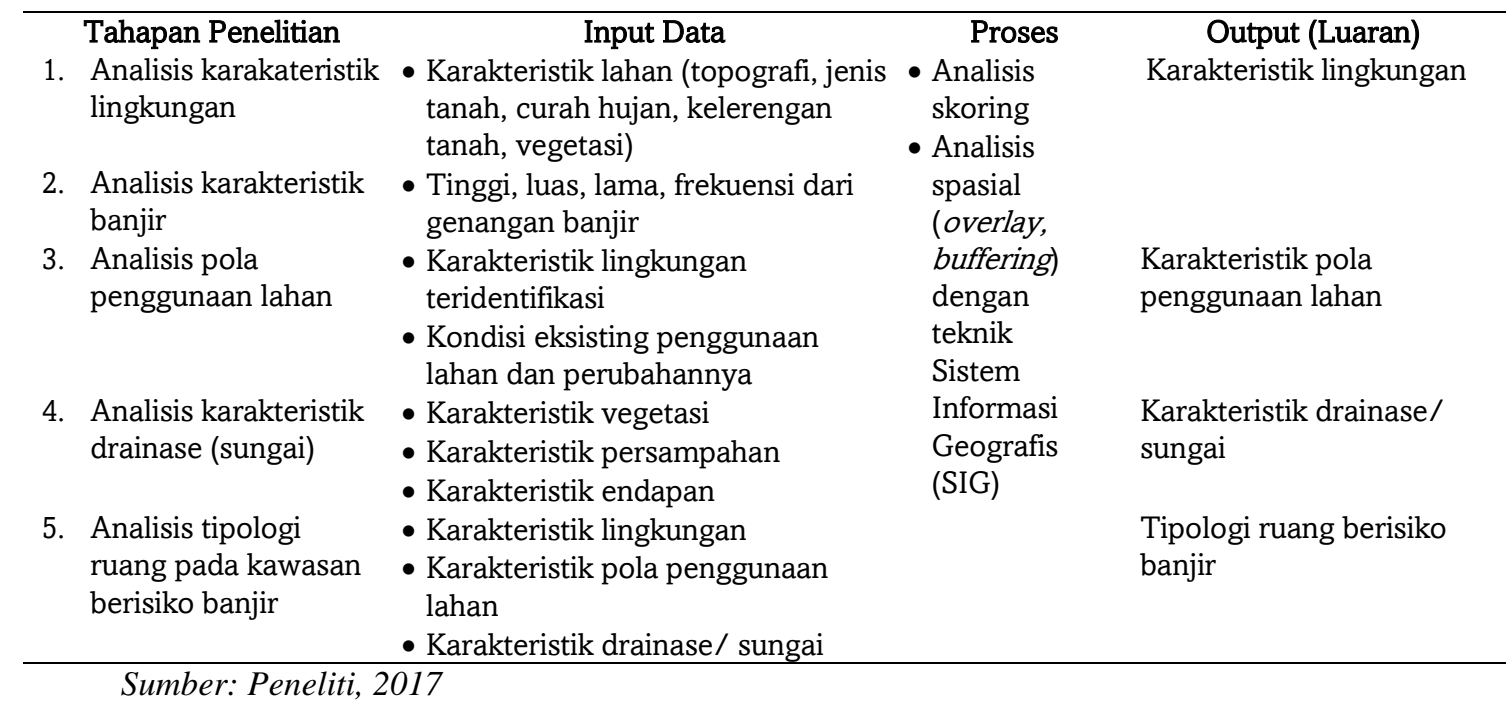

Teknik analisis spasial digunakan untuk mengindentifikasi bentuk ruang di Kawasan DAS Kali Pepe guna menunjang teknik analisis scoring yang dilakukan. Teknik analisis spasial dilakukan melalui teknik overlay (superimpose). Teknik ini terkait spasial join yakni suatu tabel atribut milik suatu layer akan ditambahkan ke dalam tabel atribut miliki layer lainnya (Prahasta, 2015). Teknik overlay ini akan menghasilkan tipologi ruang kawasan berisiko banjir.

Secara garis besar analisis yang dilakukan didasarkan pada data-data eksisting Tahun 2016, namun demikian pada analisis karakteristik banjir dan analisis pola (perubahan) penggunaan lahan didasarkan juga pada data-data kronologi kejadian banjir seperti Tahun 2007. Selain itu, analisis karakteristik banjir dan analisis pola penggunaan lahan tersebut juga didukung oleh data-data primer yang didapat dari proses wawancara dengan penduduk lokal di daerah sekitar Kali Pepe dan Kali Anyar (DAS Kali Pepe) yang telah bermukim lebih dari 30 tahun. 
Tabel 2. Kriteria Karakteristik Lahan dan Drainase

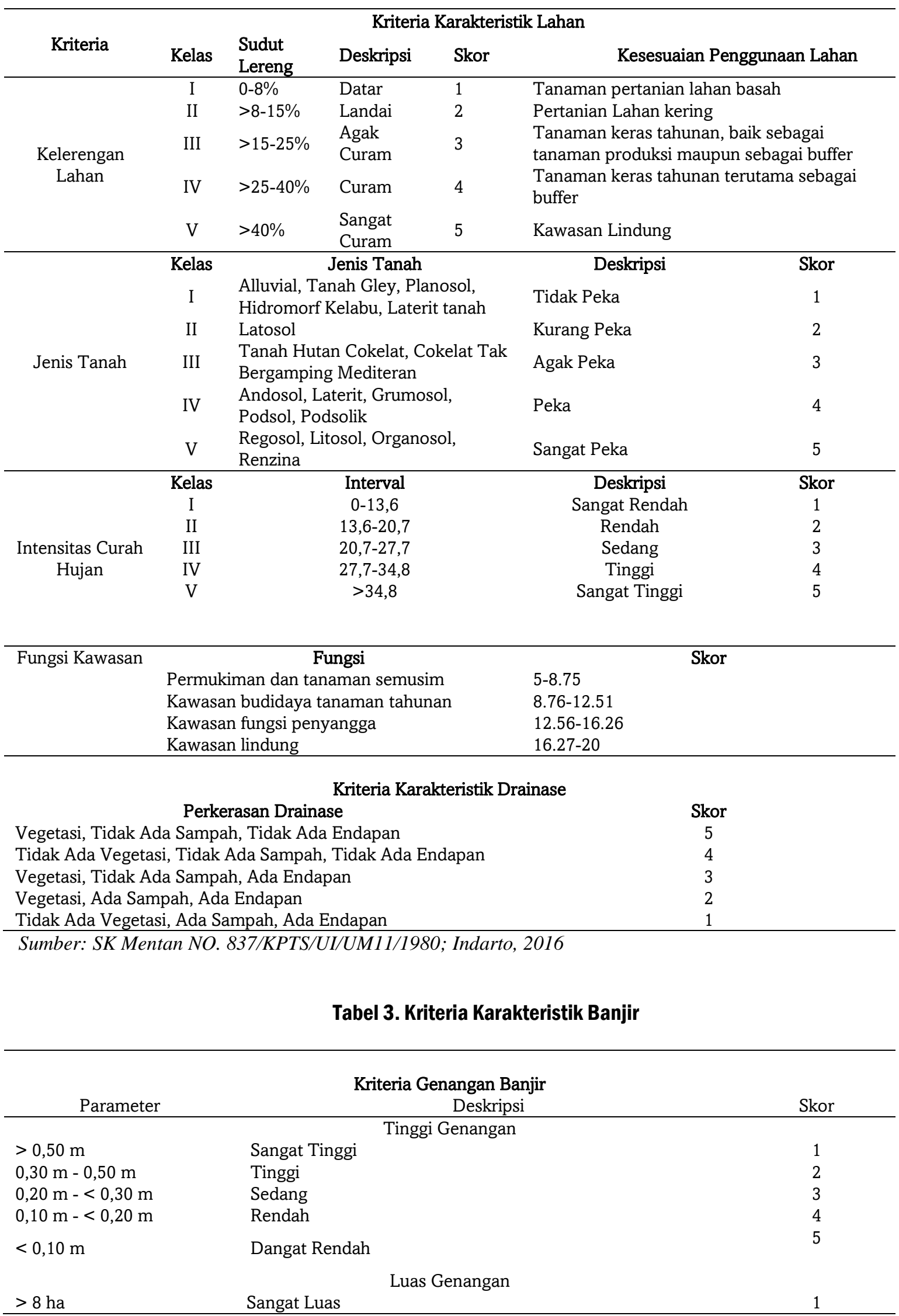




\begin{tabular}{|c|c|c|}
\hline \multicolumn{3}{|c|}{ Kriteria Genangan Banjir } \\
\hline Parameter & Deskripsi & Skor \\
\hline $4-8$ ha & Luas & 2 \\
\hline $2-<4$ ha & Sedang & 3 \\
\hline $1-<2$ ha & Sempit & 4 \\
\hline$<1$ ha & Sangat Sempit & 5 \\
\hline \multicolumn{3}{|c|}{ Lamanya Genangan } \\
\hline$>8$ jam & Sangat Lama & 1 \\
\hline $4-8$ jam & Lama & 2 \\
\hline $2-<4$ jam & Sedang & 3 \\
\hline $1-2$ jam & Sebentar & 4 \\
\hline$<1$ jam & Sangan Sebentar & 5 \\
\hline \multicolumn{3}{|c|}{ Frekuensi Genangan } \\
\hline $10 \mathrm{kali} /$ tahun & Sangat Sering & 1 \\
\hline $6 \mathrm{kali} /$ tahun & Sering & 2 \\
\hline $3 \mathrm{kali} /$ tahun & Kurang sering & 3 \\
\hline $1 \mathrm{kali} /$ tahun & Jarang & 4 \\
\hline Tidak pernah & Sangat Jarang & 5 \\
\hline
\end{tabular}
Sumber: Permen PU No.12/Prt/M/2014

\section{HASIL DAN PEMBAHASAN}

\section{Karakteristik Lahan didominasi Fungsi Kawasan Penyangga}

Penentuan fungsi kawasan didasarkan pada karakteristik lahannya. Pada Kawasan DAS Kali Pepe, sebagian besar kesesuaian fungsinya sebagai kawasan penyangga. Kawasan ini diarahkan untuk melindungi kawasan budidaya di sekitarnya. Fungsi kawasan ini mendominasi di bagian utara dan barat dari DAS Kali Pepe. Sedangkan pada wilayah selatan dari Kawasan DAS Kali Pepe, karakteristik lahannya dapat diarahkan sebagai kawasan permukiman dan budidaya tanaman semusim seperti tanaman pangan. Salah satu kriteria utama terkait fungsi permukiman dapat dikembangkan karena kelerengan wilayah yang cukup datar (berkisar 0-8 \%). Kesesuaian fungsi kawasan di DAS Kali Pepe dapat diperjelas pada Gambar 1.

\section{Dinamika Pola Penggunaan Lahan di Daerah Sempadan Sungai}

Pola penggunaan lahan dan sebaran bangunannya merupakan salah satu kriteria penentuan tipologi ruang. Penggunaan lahan di sekitar kawasan DAS Kali Pepe didominasi oleh penggunaan lahan permukiman, serta perdagangan dan jasa. Pada Kawasan DAS Kali Pepe lama (bagian selatan), tingkat kepadatan bangunan tergolong tinggi, karena kawasan tersebut merupakan kawasan pusat kota yang pembangunannya lebih cepat dibandingkan pada kawasan bagian utara atau di sekitar kawasan DAS Kali Pepe baru. Perubahan pola penggunaan lahan di Kawasan DAS Kali Pepe tergolong dinamis. Sebagai contoh, selama kurang lebih 10 tahun pada kawasan ini terdapat perubahan guna lahan seperti terjadi pada kawasan sekitar sempadan Sungai Kali Anyar (DAS Kali Pepe Baru) di Kelurahan Mojosongo dan Kelurahan Jebres. Upaya pengurangan risiko banjir menjadi salah satu faktor yang mempengaruhi perubahan pola penggunaan lahan yang terjadi. Sebagai contoh, sebelum Tahun 2006 kawasan tersebut masih merupakan kawasan permukiman. Guna mengurangi risiko banjir, Pemerintah Kota Surakarta merelokasi warga dari daerah tersebut ke Kelurahan Mojosongo bagian utara, dan kemudian memanfaatkan daerah sempadan sungai tersebut sebagai ruang terbuka hijau yang dapat digunakan untuk kegiatan publik. 


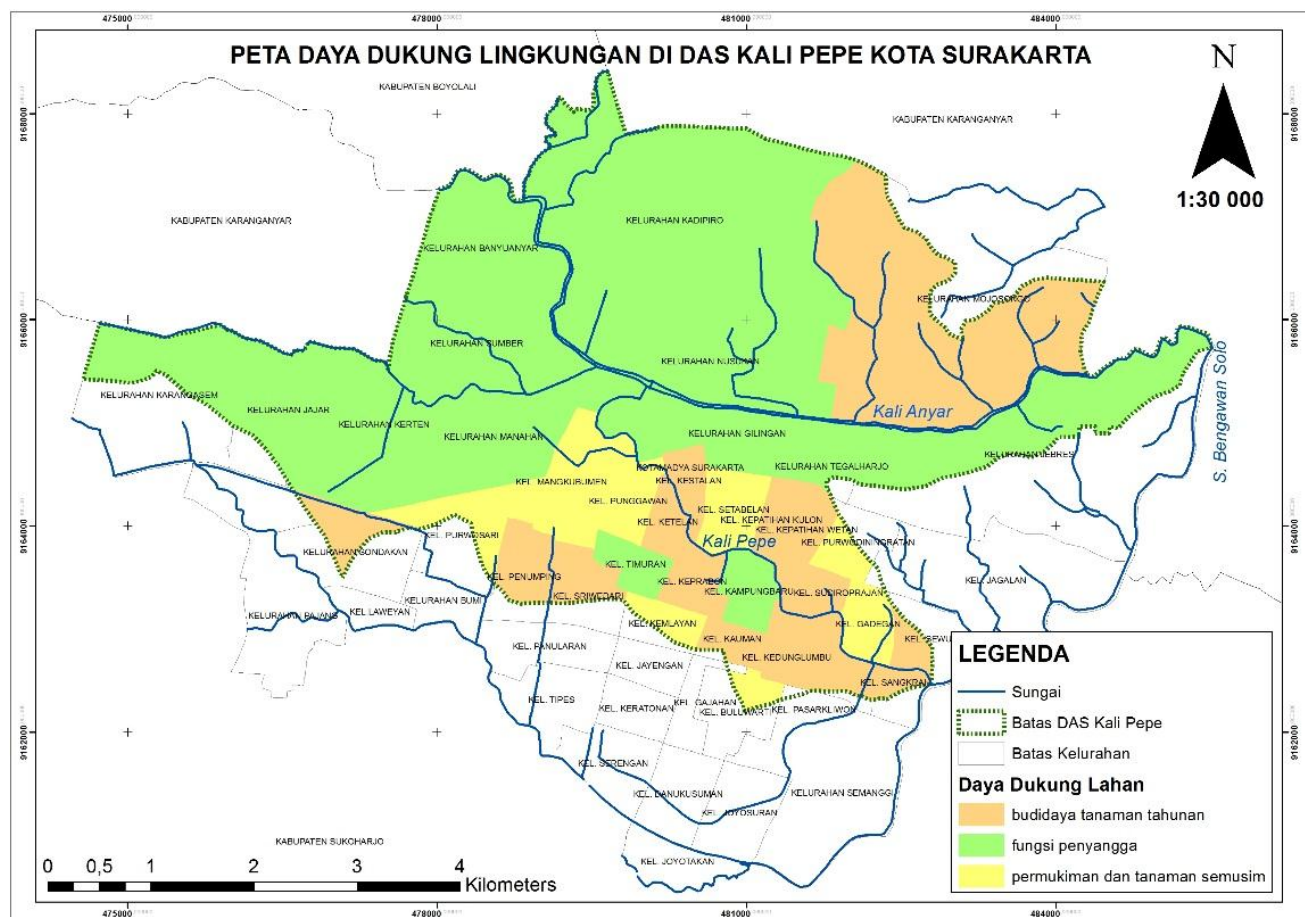

Sumber: Analisis, 2017

Gambar 1. Peta Kesesuaian Fungsi Kawasan di DAS Kali Pepe

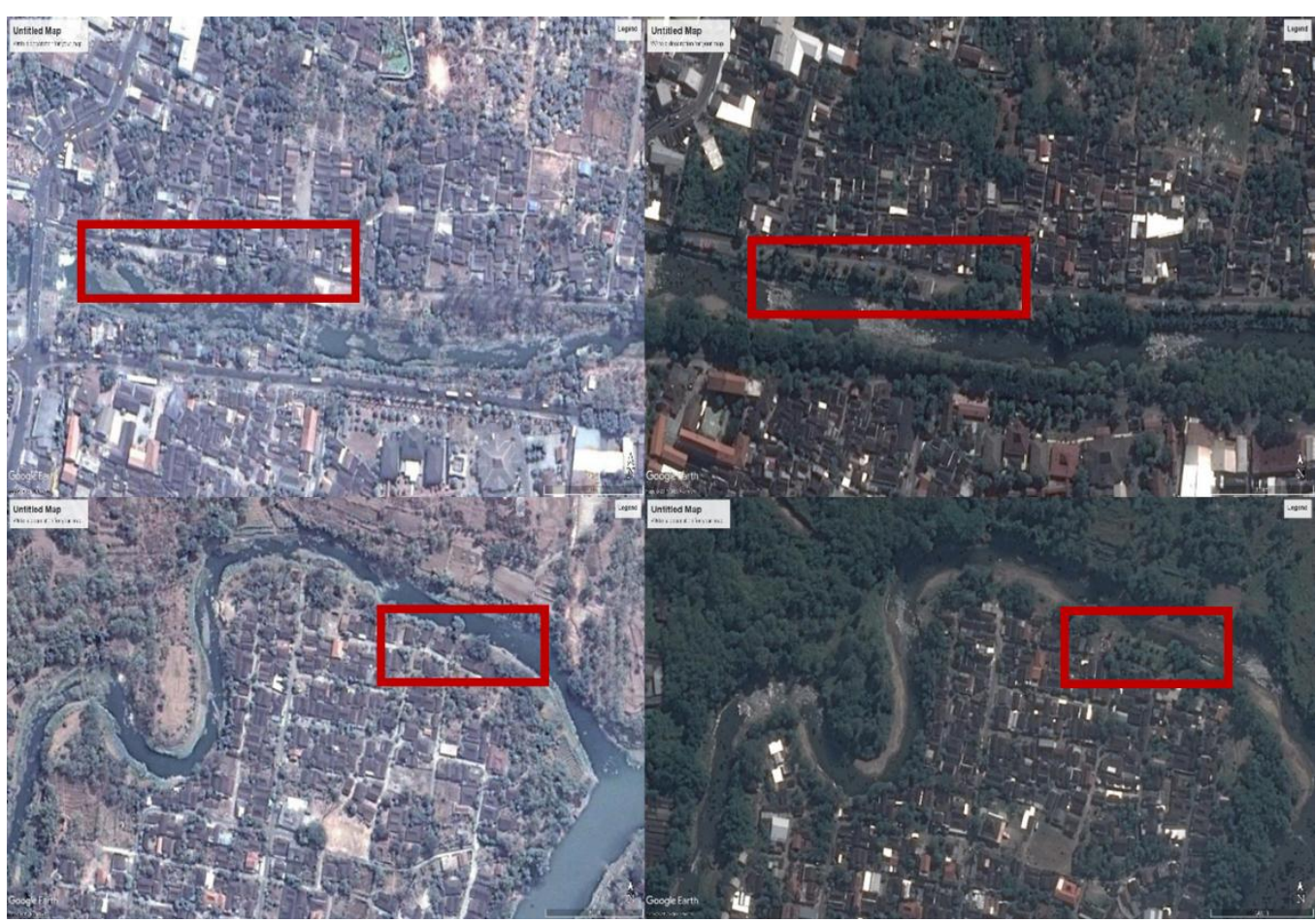

Sumber: Google Earth, 2007 dan 2016

Gambar 2. Contoh Perubahan Pola Penggunaan Lahan di Sempadan Kali Pepe Tahun 2007 dan 2016 


\section{Penurunan Risiko Banjir di Bagian Hulu dan Hilir Kawasan DAS Kali Pepe}

Analisis karakteristik banjir di DAS Kali Pepe didasarkan pada kriteria-kriteria meliputi ketinggian banjir, lama genangan, frekuensi banjir, dan luasan genangan. Berdasarkan data wawancara dengan penduduk lokal di sekitar Kawasan DAS Kali Pepe diketahui bahwa kejadian banjir yang signifikan terjadi pada Tahun 1966, 2007, dan 2016. Hasil analisis scoring karakteristik banjir di DAS Kali Pepe didominasi oleh penilaian dampak banjir tinggi dan sangat tinggi. Hal ini menunjukkan bahwa Kawasan DAS Kali Pepe ini memiliki risiko banjir yang tinggi. Dampak banjir di DAS Kali Pepe, terutama terjadi di wilayah di dekat aliran sungai. Namun demikian, Kawasan DAS Kali Pepe jika dilihat dari kecenderungan dampak banjir dari tahun-tahun sebelumnya mengalami penurunan.

Tabel 4. Karakteristik Banjir DAS Kali Pepe

\begin{tabular}{|c|c|c|c|}
\hline Kelurahan & Keterengan & Skor Akhir & Dampak Banjir \\
\hline Sudiroprajan & Banjir 2007 & 12 & Sedang \\
\hline Stabelan & Banjir 1966 & 9 & Tinggi \\
\hline Kepatihan Kulon & Banjir 1966 & 9 & Tinggi \\
\hline Ketelan & Banjir 1966 & 10 & Tinggi \\
\hline Kepatihan Wetan & Banjir 1966 & 11 & Tinggi \\
\hline Timuran & Banjir 2016 & 12 & Sedang \\
\hline Kedunglumbu & Banjir 2007 & 10 & Tinggi \\
\hline Sondakan & Banjir 2016 & 9 & Tinggi \\
\hline Purwodiningratan & Banjir 2007 & 9 & Tinggi \\
\hline Kestalan & Banjir 1966 & 13 & Sedang \\
\hline Kauman & Banjir 2007 & 9 & Tinggi \\
\hline Mojosongo & Banjir 1966 & 14 & Sedang \\
\hline Timuran & Banjir 2007 & 7 & Sangat Tinggi \\
\hline Nusukan & Banjir 2007 & 8 & Sangat Tinggi \\
\hline Banyuanyar & Banjir 2007 & 10 & Tinggi \\
\hline Sangkrah & Banjir 2007 & 7 & Sangat Tinggi \\
\hline Sangkrah & Banjir 1966 & 7 & Sangat Tinggi \\
\hline Keprabon & Banjir 1966 & 7 & Sangat Tinggi \\
\hline Banyuanyar & Banjir 2016 & 10 & Tinggi \\
\hline Kauman & Banjir 1966 & 8 & Sangat Tinggi \\
\hline Kadipiro & Banjir 1966 & 9 & Tinggi \\
\hline Jebres & Banjir 1966 & 14 & Sedang \\
\hline Gandekan & Banjir 2016 & 7 & Sangat Tinggi \\
\hline Gandekan & Banjir 2007 & 7 & Sangat Tinggi \\
\hline Sudiroprajan & Banjir 1966 & 7 & Sangat Tinggi \\
\hline Nusukan & Banjir 1966 & 7 & Sangat Tinggi \\
\hline Sewu & Banjir 2007 & 6 & Sangat Tinggi \\
\hline
\end{tabular}

Sumber: Analisis, 2017 

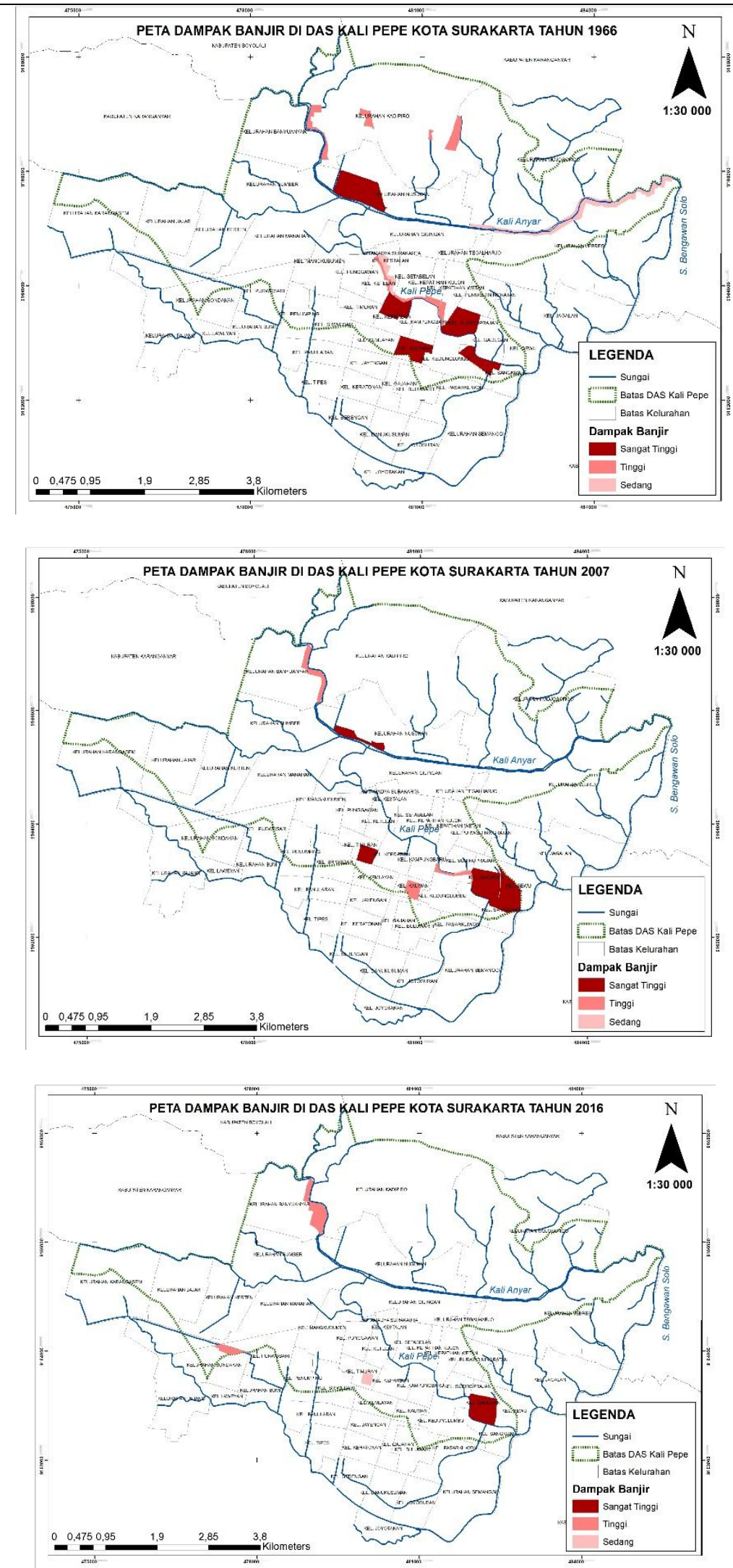

Sumber: Data Primer, 2017

Gambar 3. Peta Dampak Banjir DAS Kali Pepe Tahun 1966 (atas), 2007 (tengah), 2016 (bawah) 


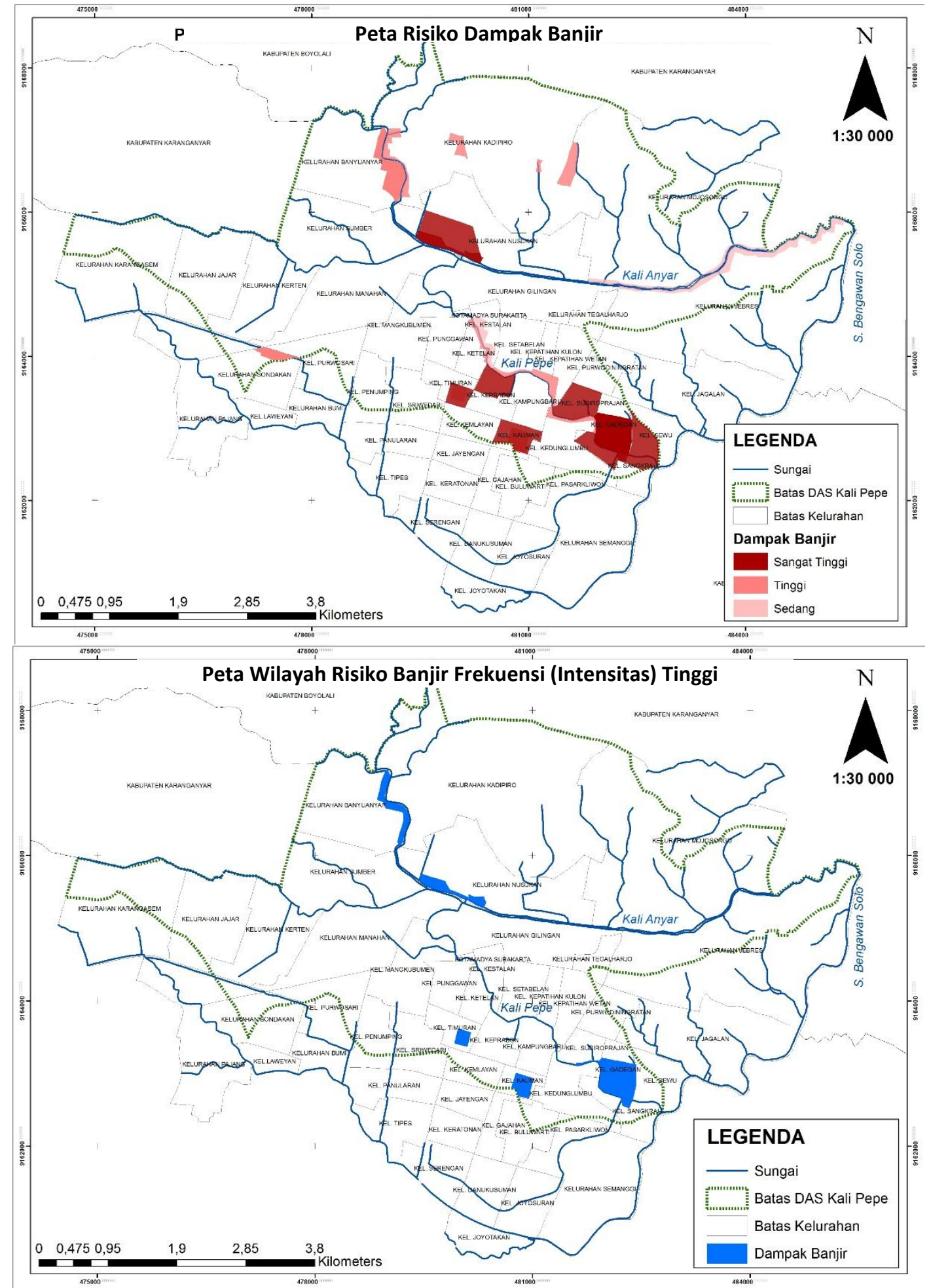

Sumber: Data Primer, 2017

Gambar 4. Peta Risiko Dampak Banjir dan Wilayah Risiko Frekuensi Banjir Intensitas Tinggi di DAS Kali Pepe 
Berdasarkan hasil teknik analisis spasial overlay, dapat diketahui dampak banjir di DAS Kali Pepe. Beberapa variasi risiko dampak banjir terdapat di Kawasan DAS Kali Pepe. Risiko dampak banjir sangat tinggi dan tinggi berada di keseluruhan Wilayah Kelurahan Gandekan, dan beberapa bagian wilayah kelurahan lainnya seperti Kelurahan Sewu, Sudiroprajan, Keprabon, Kauman, Timuran, Banyuanyar dan Kadipiro. Sedangkan wilayah risiko banjir intensitas tinggi berada hanya di Kelurahan Gandekan, Timuran, Kauman, Banyuanyar dan Nusukan. Hal ini menunjukkan bahwa risiko banjir di Kawasan DAS Kali Pepe terjadi di bagian hilir maupun hulunya. Fakta ini mendasari perlunya integrasi sistem hulu-hilir dalam pertimbangan manajemen ruang di DAS Kali Pepe.

\section{Tipologi Ruang Berisiko Banjir di Kawasan DAS Kali Pepe}

Tipologi ruang DAS Kali Pepe didapatkan dari overlay karakteristik lingkungan (lahan dan drainase), pola penggunaan lahan dan sebaran bangunan, dan karakteristik banjir. Dari overlay tersebut diketahui bahwa Kawasan DAS Kali Pepe memiliki 42 tipologi ruang. Setiap jenis ruang memiliki minimal satu kriteria karakteristik yang berbeda dengan jenis ruang yang lainnya baik dari kriteria daya dukung lingkungan (karakteristik lahan dan karakteristik drainase), karakteristik pola penggunaan lahan, ataupun karakteristik banjirnya. Berikut ini merupakan gambaran tipologi ruang di DAS Kali Pepe.

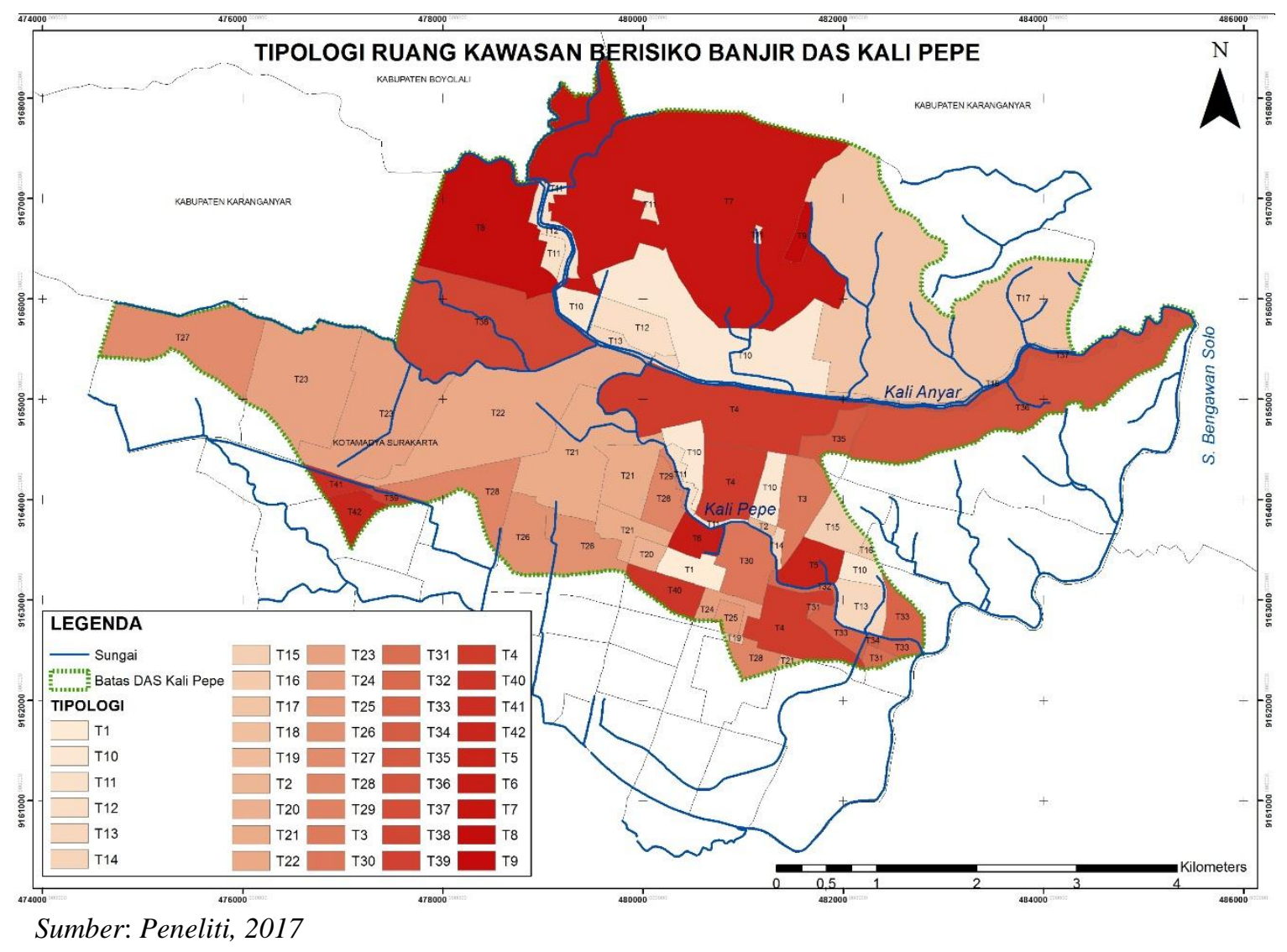

Gambar 5. Peta Tipologi Tata Ruang Kawasan Risiko Banjir DAS Kali Pepe

Dari 42 jenis ruang yang ada di Kawasan DAS Kali Pepe, hanya 18 jenis ruang yang merupakan wilayah berisiko banjir. Wilayah yang mengalami dampak banjir sangat tinggi berada di kawasan permukiman yang dominasinya berdensitas bangunan dan penduduk 
padat seperti di Kelurahan Gandekan, Nusukan, dan Sangkrah. Wilayah ini berada di kelerangan datar maupun landai, jenis tanah mediteran coklat, dan dipastikan memiliki perkerasan drainase buruk.

Sedangkan wilayah yang memiliki dampak banjir tinggi berada di sebagian Kelurahan Sudiroprajan, Keprabon, Banyuanyar, Nusukan, Timuran, Kauman, Sewu, dan Sangkrah. Pada wilayah ini penggunaan lahannya bervariasi berupa permukiman, perdagangan, perkantoran, dan pendidikan. Kelerengan datar mendominasi di wilayah ini. Jenis tanahnya bervariasi berupa mediteran coklat, regosol kelabu. Sebagian besar perkerasan drainasenya buruk.

Wilayah yang memiliki dampak banjir sedang meliputi sebagian Kelurahan Kepatihan Kulon, Kadipiro, Kestalan, Setabelan, Banyuanyar, Kepatihan Wetan, Mojosongo, Kauman, Ketelan, Kedunglumbu, Jebres, dan Sondakan. Wilayah ini memiliki keseluruhan kriteria karakteristik yang bervariasi, baik dari penggunaan lahan, karakteristik lahan, dan perkerasan drainasenya.

Tabel 5. Tipologi Ruang Berisiko Banjir di Kawasan DAS Kali Pepe

\begin{tabular}{|c|c|c|c|c|c|c|c|c|}
\hline \multirow[b]{2}{*}{ No } & \multirow[b]{2}{*}{ Kelurahan } & \multirow{2}{*}{$\begin{array}{l}\text { Dampak } \\
\text { Banjir }\end{array}$} & \multirow{2}{*}{$\begin{array}{l}\text { Penggunaan } \\
\text { Lahan }\end{array}$} & \multicolumn{3}{|c|}{ Karakteristik Lahan } & \multirow{2}{*}{$\begin{array}{c}\text { Perkerasan } \\
\text { Drainase }\end{array}$} & \multirow[b]{2}{*}{ Tipologi } \\
\hline & & & & Kelerengan & $\begin{array}{c}\text { Jenis } \\
\text { Tanah }\end{array}$ & $\begin{array}{l}\text { Curah } \\
\text { Hujan }\end{array}$ & & \\
\hline 1 & $\begin{array}{l}\text { Kepatihan } \\
\text { Kulon }\end{array}$ & Banjir Sedang & Perdagangan & Datar & $\begin{array}{c}\text { Mediteran } \\
\text { Coklat }\end{array}$ & Rendah & Buruk & $\mathrm{T} 2$ \\
\hline 2 & Sudiroprajan & Banjir Tinggi & $\begin{array}{l}\text { Permukiman, } \\
\text { Perdagangan }\end{array}$ & Datar & $\begin{array}{c}\text { Mediteran } \\
\text { Coklat }\end{array}$ & Rendah & Buruk & T5 \\
\hline 3 & Keprabon & Banjir Tinggi & $\begin{array}{l}\text { Permukiman, } \\
\text { Perkantoran }\end{array}$ & Datar & $\begin{array}{c}\text { Mediteran } \\
\text { Coklat }\end{array}$ & Rendah & Buruk & T6 \\
\hline 4 & Kadipiro & Banjir Sedang & $\begin{array}{l}\text { Permukiman, } \\
\text { Sawah }\end{array}$ & Datar & $\begin{array}{c}\text { Mediteran } \\
\text { Coklat }\end{array}$ & Rendah & Buruk & T9 \\
\hline 5 & $\begin{array}{l}\text { Kestalan, } \\
\text { Setabelan, } \\
\text { Kadipiro, } \\
\text { Banyuanyar }\end{array}$ & Banjir Sedang & Permukiman & Datar & $\begin{array}{c}\text { Mediteran } \\
\text { Coklat }\end{array}$ & Rendah & Buruk & $\mathrm{T} 11$ \\
\hline 6 & $\begin{array}{l}\text { Banyuanyar, } \\
\text { Nusukan }\end{array}$ & Banjir Tinggi & Permukiman & Datar & $\begin{array}{c}\text { Mediteran } \\
\text { Coklat }\end{array}$ & Rendah & Buruk & $\mathrm{T} 12$ \\
\hline 7 & $\begin{array}{l}\text { Nusukan, } \\
\text { Gandekan }\end{array}$ & $\begin{array}{l}\text { Banjir Sangat } \\
\text { Tinggi }\end{array}$ & Permukiman & Datar & $\begin{array}{c}\text { Mediteran } \\
\text { Coklat }\end{array}$ & Rendah & Buruk & $\mathrm{T} 13$ \\
\hline 8 & $\begin{array}{l}\text { Kepatihan } \\
\text { Wetan }\end{array}$ & Banjir Sedang & Perdagangan & Datar & $\begin{array}{l}\text { Mediteran } \\
\text { Coklat } \\
\text { Gromosol }\end{array}$ & Rendah & Baik & $\mathrm{T} 14$ \\
\hline 9 & Mojosongo & Banjir Sedang & Permukiman & Datar & $\begin{array}{l}\text { Kelabu } \\
\text { Tua }\end{array}$ & Rendah & Buruk & $\mathrm{T} 18$ \\
\hline 10 & Timuran & Banjir Tinggi & Perdagangan & Datar & $\begin{array}{l}\text { Regosol } \\
\text { Kelabu }\end{array}$ & Rendah & Buruk & $\mathrm{T} 20$ \\
\hline 11 & Kauman & Banjir Sedang & $\begin{array}{c}\text { Permukiman, } \\
\text { Kesehatan }\end{array}$ & Datar & $\begin{array}{l}\text { Regosol } \\
\text { Kelabu }\end{array}$ & Rendah & Baik & T24 \\
\hline 12 & Kauman & Banjir Tinggi & $\begin{array}{l}\text { Permukiman, } \\
\text { Pendidikan }\end{array}$ & Datar & $\begin{array}{l}\text { Regosol } \\
\text { Kelabu }\end{array}$ & Rendah & Baik & T25 \\
\hline 13 & Ketelan & Banjir Sedang & Permukiman & Datar & $\begin{array}{l}\text { Regosol } \\
\text { Kelabu }\end{array}$ & Rendah & Baik & T29 \\
\hline 14 & Kedunglumbu & Banjir Sedang & Permukiman & Landai & $\begin{array}{c}\text { Mediteran } \\
\text { Coklat }\end{array}$ & Rendah & Buruk & T32 \\
\hline 15 & $\begin{array}{l}\text { Sewu, } \\
\text { Sangkrah }\end{array}$ & Banjir Tinggi & Permukiman & Landai & $\begin{array}{c}\text { Mediteran } \\
\text { Coklat }\end{array}$ & Rendah & Buruk & T33 \\
\hline 16 & Sangkrah & $\begin{array}{l}\text { Banjir Sangat } \\
\text { Tinggi }\end{array}$ & Permukiman & Landai & $\begin{array}{c}\text { Mediteran } \\
\text { Coklat }\end{array}$ & Rendah & Buruk & T34 \\
\hline 17 & Jebres & Banjir Sedang & Permukiman & Landai & $\begin{array}{l}\text { Gromosol } \\
\text { Kelabu } \\
\text { Tua }\end{array}$ & Rendah & Buruk & Т37 \\
\hline 18 & Sondakan & Banjir Sedang & Perdagangan & Landai & $\begin{array}{l}\text { Regosol } \\
\text { Kelabu }\end{array}$ & Rendah & Baik & Т39 \\
\hline
\end{tabular}

Sumber: Analisis, 2017 
Kondisi-kondisi tersebut menunjukkan bahwa karakteristik lahan cenderung tidak berkorelasi terhadap intesitas dampak banjir. Sedangkan pola penggunaan lahan memiliki kecenderungan berkorelasi terhadap intensitas dampak banjir. Selain itu karakteristik perkerasan drainase juga cenderung berkorelasi dengan dampak banjir. Berdasarkan faktafakta tersebut, model penataan ruang di Kawasan DAS Kali Pepe dapat dikonsentrasikan pada rekayasa ruang kawasan permukiman, terutama yang memiliki intensitas kepadatan tinggi dari bangunan dan penduduk. Ruang-ruang terbangun di daerah sekitar aliran sungai perlu dibatasi pertumbuhannya karena penambahan ruang terbangun berkorelasi dengan risiko dampak banjir. Disamping itu, rekayasa infrastruktur sebaiknya memperhatikan pada sistem aliran sungai hulu dan hilir, karena terkait dengan efektivitas sistem drainase yang berkorelasi terhadap risiko dampak banjir.

\section{KESIMPULAN}

Tipologi ruang di Kawasan DAS Kali Pepe ditinjau dari segi daya dukung lingkungannya terdiri atas 42 jenis ruang. Namun demikian, hanya 18 jenis ruang yang merupakan wilayah berisiko banjir. 18 jenis ruang tersebut merupakan kawasan-kawasan yang memiliki dominasi intensitas lahan terbangun yang tinggi (sebagian besar permukiman padat) dan karakteristik drainase yang buruk. Sedangkan karakteristik lahan di 18 jenis ruang tersebut bervariasi dan tidak berkorelasi signifikan terhadap intensitas dampak banjir. Dari 18 jenis ruang tersebut, kawasan-kawasan yang memiliki intensitas dampak banjir sangat tinggi dan tinggi sebagian besar terletak di DAS Kali Pepe Lama (aliran sungai yang mengalir ke arah tenggara) terutamanya bagian hilir, sedangkan pada DAS Kali Pepe Baru (aliran sungai yang mengalir ke arah timur/ Kali Anyar) hanya terdapat kawasan-kawasan yang memiliki intensitas dampak banjir sedang. Pada DAS Kali Pepe Lama merupakan kawasankawasan pusat perkotaan dan embrio morfologi Kota Surakarta yang terdapat intensitas kepadatan bangunan tinggi. Sedangkan 24 jenis ruang yang tidak berisiko banjir, sebagian besar kawasan-kawasan yang berada tidak berbatasan langsung dengan sempadan Kali Pepe, dan memiliki intensitas bangunan yang relatif lebih rendah dibandingkan dengan intensitas bangunan pada kawasan-kawasan yang berada di 18 jenis ruang berisiko banjir.

Berdasarkan hasil tersebut, kesimpulan dari penelitian ini yakni pola penggunaan lahan (karakteristik kawasan terbangun), serta karakteristik drainase memiliki pengaruh signifikan terhadap tipologi ruang berisiko banjir. Berdasarkan tipologi kawasan yang telah terindentifikasi, dapat diarahkan untuk model penataan ruang di kawasan berisiko banjir harus mempertimbangkan pada prioritas penanganan kawasan permukiman utamanya dengan intensitas kepadatan bangunan tinggi, pembatasan ruang terbangun di kawasankawasan sekitar aliran sungai primer, dan rekayasa infrastruktur drainase yang harus mempertimbangkan kesatuan sistem hidrologi hulu-hilir aliran sungai.

\section{UCAPAN TERIMA KASIH}

Para penulis mengucapkan terima kasih kepada Universitas Sebelas Maret (UNS) yang telah membiayai penelitian ini dalam skema pendanaan Penerimaan Negara Bukan Pajak (PNBP) Tahun Anggaran 2017. 


\section{DAFTAR PUSTAKA}

Badan Nasional Penanggulangan Bencana, “Sebaran Kejadian Bencana Per Kabupaten/ Kota 1815 s/d 2017”, Data dan Informasi Bencana Indonesia [Web], diakses 15 Februari 2017,http://dibi.bnpb.go.id/DesInventar/dashboard.jsp?countrycode=id\&continue=y\&lang= ID

Brody, S.D., Highfield, W.E., 2013, “Open space protection and flood mitigation: A national study”, Land Use Policy Vol. 32, pp. 89-95

Gilbuena Jr., R, Kawamura, A., Medina, R., Nakagawa, N., Amaguchi, H., 2013, "Environmental impact assessment using a utility-based recursive evidential reasoning approach for structural flood mitigation measures in Metro Manila, Philippines”, Journal of Environmental Management, Vol. 131, pp. 92-102.

Hong, Y, Adhikari, P., Gourley, J.J., 2013, “Flood Hazard and Disaster”, in: Bobrowsky, P.T., Encyclopedia of Natural Hazards, Dordrecht: Springer Science+Business Media.

Indarto. 2016. Hidrologi: Analisis dan Tool Untuk Interpretasi Hidograf Alitan Sungai. Jakarta: PT. Bumi Aksara Group

Kousky, C \& Walls, M., 2014, "Analysis Floodplain conservation as a flood mitigation strategy: Examining costs and benefits”, Ecological Economics Vol. 104, pp. 119-128.

Liao, K., Le, T.A., Nguyen, K.V., 2016, "Urban design principles for flood resilience: Learning from the ecological wisdom of living with floods in the Vietnamese Mekong Delta", Landscape and Urban Planning, Vol. 155, pp. 69-78.

Miladan, N., 2016, “Communities' Contributions to Urban Resilience Process: a Case Study of Semarang City (Indonesia) Toward Coastal Hydrological Risk", PhD Disertation in Spatial Planning and Urbanism, Université Paris-Est and Universitas Diponegoro.

Mohit, M.A., Sellub, G.M., 2013, "Mitigation of Climate Change Effects through Non-structural Flood Disaster Management in Pekan Town, Malaysia”, Procedia - Social and Behavioral Sciences, Vol. 85, pp. 564 573.

Pemerintah Kota Surakarta, 2016, “BPBD Kota Surakarta Waspadai 21 Kelurahan Rawan Banjir”, Berita Kota [Web], diakses 15 Februari 2017, http://www.surakarta.go.id/konten/bpbd-kota-surakarta-waspadai21-kelurahan-rawan-banjir

Preahasta, Eddy. 2015. SIG Tutorial ArcGIS untuk Bidang Geodesi \& Geomatika. Bandung: Informatika.

Ran, J., Nedovic-Budic, Z., 2016, "Integrating spatial planning and flood risk management: A new conceptual framework for the spatially integrated policy infrastructure", Computers, Environment and Urban Systems, Vol. 57, pp. 68-79

Soemarwoto, Otto. 2000. Analisa Dampak Lingkungan. Yogyakarta: Gadjahmada University Press.

Sugiono. 2011. Metode Penelitian Kuantitatif dan Kualitatif. Bandung. CV. Afabeta

Tingsanchali, T., 2011, “Urban Flood Disaster Management”, Procedia Engineering, vol. 32, pp. 25-37.

United Nations Office for Disaster Risk Reduction (UNISDR), 2012, “Annual Report 2011”, UNISDR [Web], diakses 15 Februari 2017, http://www.unisdr.org/files/27627_ar2011v2.pdf

Undang-undang No. 24 Tahun 2007 tentang Penanggulangan Bencana

Wisner, B., Blaikie, P. Cannon, T, Davis, I., 2003, At risk: natural hazards, people's vulnerability and disasters, London/ New York: Routledge. 